\title{
Digital Tools and Information Needs Assessment for Efficient Deviation Handling in SMEs
}

\author{
Zuhara CHAVEZ ${ }^{\mathrm{a}, 1}$, Jannicke BAALSRUD HAUGE ${ }^{\mathrm{a}}$, Monica BELLGRAN ${ }^{\mathrm{a}}$, \\ Per GULLANDER ${ }^{b}$, Mats JOHANSSON ${ }^{c}, \operatorname{Lars~MEDBO}^{c}, \mathrm{Per}_{\mathrm{MEDBO}}{ }^{c}$, \\ Mikael STRÖM ${ }^{\mathrm{b}}$ \\ ${ }^{a}$ KTH Royal Institute of Technology, \\ Dept of Sustainable Production Development, Södertälje, Sweden. \\ ${ }^{\mathrm{b}}$ RISE, Materials \& Production, \\ Dept Product Realization Methodology, Mölndal, Sweden. \\ c Chalmers University of Technology, \\ Dept Technology Management and Economics, Göteborg, Sweden.
}

\begin{abstract}
In a time of change focusing on the application of technology, there is a high risk of underestimating the compliance of internal needs and adaption to context. The research study employs a qualitative approach using the case study methodology. The source of data comes from five different manufacturing companies categorized as Small to Medium Size Enterprises (SMEs). A multidisciplinary team performed semi-structured interviews and fieldwork at each site, along with regular online meetings with the partners. The study employs five dimensions of the information quality perspective to assess information utilized to support deviation handling and connects the information quality deficiencies to the digital tools' impact. The empirical findings indicate the need for the companies to perform a requirement analysis of information needs before the adoption of digital systems or digital tools, to assess their current state in terms of data and information. The paper discusses the impact digital tools may have on deviation management in SMEs and under which circumstances digital tools could improve deviation management. Lastly, this paper intends to shed light on the utilization of digital technologies for disturbance handling on the production shop floor.
\end{abstract}

Keywords. Production disturbances, Deviation management, Information need, SME, Digital transformation.

\section{Introduction}

Digitalization within the manufacturing context is receiving high attention today and considered as a means to increase production performance and overall customer value. More factories move toward implementing high-tech methodologies [1], like the implementation of Cyber-Physical Systems (CPS) and the Internet of Things (IoT). Since digitilization within manufacturing often is conceptually described, as e.g. Industry 4.0 concept (I4.0), there is a need for operationalizing and demonstration such the concept through real cases.

\footnotetext{
${ }^{1}$ Corresponding Author: zuhar@kth.se
} 
Self-organization and self-optimization are typical aspects of I4.0 that generally do not match the characteristics of today's existing IT integrated solutions. Systems tend to be complex and centrally organized, and thus costly to adapt and maintain. This restricts flexible integration of IT systems and self-organization of manufacturing processes. Such difficulties are faced by industry in the transformation to smarter solutions, being governed and restricted by legacy systems and operative requirements. The situation becomes even more challenging when restrained by limited IT budget and know-how, which is the case for many SMEs [2], who struggle to adapt to external market forces and to take the next step in expanding their businesses [3]. Therefore, SMEs need special guidance and support to manage digital transformation (DT).

In order to realize the digital, sensing and smart factory it is important to address practical realization of digital real-time data monitoring [4], [5]. Thus providing possibility to identify deviations in the production and delays in the logistics network in real-time. Another related challenge is to achieve robust production systems that have the ability to absorb disturbances without failing or breaking [3]. Proper implementation of I4.0 concepts and adopting new technologies will contribute to more robust systems. However, if digitalization is made incorrectly, a less robust system may result. Disruptions or deviations from planned performance may have many sources, e.g. in equipment, planning changes, lack of material or resources, and changed orders. Furthermore, the robustness concept can be applied at many levels, from components and machines, up to production and logistics level, i.e. it deals with the capability of being able to deliver to customers, despite deviations in system or context. In order to achieve robustness, the system should be either designed to permit deviations without causing disturbances, or deviations must be handled by taking counter-measure actions or making relevant adaptations. From an industrial business perspective, it is vital to improve the capacity to handle deviations and disturbances in production. A study [6] showed an average of $51 \%$ Overall Equipment Efficiency (OEE) in 94 Swedish companies (years 2006 to 2012), demonstrating great potential for improving capacity, productivity, as well as ecologic sustainability.

Research related to I4.0 implementation is novel and extensively focused on big enterprises. Specifically, research on how SMEs transition to I4.0 paradigm or early phases of digitalization is scarce [7], [8]. Studies on DT supporting deviation management in the context of an SME are to the best of our knowledge lacking, although being of utmost importance since the SMEs are the backbone of the Swedish manufacturing industry. Therefore, the purpose of this paper is to understand the as-is situation, needs, and the utilization of new technologies or digital systems for more efficient handling of deviation management in SMEs. The research sets out to build knowledge on the impact of digital tools on deviation management in SMEs.

\section{Theoretical background}

\subsection{Digital transformation and deviation management}

Digital Transformation (DT) can generally be defined as the usage of technologies to enable major business improvements i.e. streamlining operations, creating new business models, etc. However, it envelops more than technology use and includes the alignment to the organization and the environment [9], [10]. A specific strategy for the initiation of digitalization activities must be defined and supported by the management, which is 
responsible for the initiation of digitalization activities [11]. Guidelines on DT are thus imperative, the approach within this work is not to apply a general rigid assessment but to enable companies to develop their individual transformation process which is important in order to identify, evaluate and utilize the specific I4.0 potentials of the respective company [11]. Some examples of guidelines on DT and implementation of I4.0 elements [11]-[15] attempt to define stage process models to guide and train companies to identify new opportunities for digital diversification and to connect company vision and I4.0 roadmaps. However, those models tend to lack the connection to deviation management.

Research focusing on disturbance handling in production mainly presents solutions aimed to decrease processes' variability [10], improve measurement system [16] and monitor production processes [2]. However, none of the identified research papers present the types of deviations they focus, nor do they relate to the effects on deviation management. One common factor presented in the studies is the focus on variation analysis in the production processes and operations; such studies agree upon the necessity to control and stabilize variation to reduce deviations hence disturbances [10], [16]-[18]. However, the focus of these studies is limited to process variation, i.e. far from the full integration aim with I4.0 or a DT.

Disturbances and deviations as such are often assessed when addressing resilience and robustness from different perspectives. For instance, research focusing on analyzing the variation and its adjustability [17] highlights the principle of adjustability as one of the aspects that comply with I4.0 demands when focusing on proactive feedback. The deviation is mostly mentioned as variation in the product related to quality and design [17]. Recent research analyzes variation in terms of manufacturing disturbances, propagation and their effects by proposing to use the Max-Plus algebra [19], while other focus directly on resilience and the characteristics necessary to increase resilience [20]. This study makes a clear distinction between resilience and robust system and highlights that the objective of I 4.0 systems is to be robust i.e. the ability to absorb manufacturing disruptions without failing or breaking.

\subsection{Deviation management supported by the improvement of information quality.}

Many manufacturing companies are still at the very beginning of collecting and using data gathered during production processes, dealing with issues like major parts of the collected data being missed, outdated or biased and far away from real-time.

Digital tools offer the opportunity to simplify data gathering, provide accurate information and feedback for reliable production planning and control [5]. Several digital software tools and methodologies are available for gathering and converting data into proper information. However, a major challenge, often overlooked, is to determine which information is needed by different users in order to gain value [21]. Handling data will be a challenge for organizations in the transition to digital ways of working [1], [20]. Therefore, it is of importance to consider the quality of information, focusing both on freedom from deficiencies as well as meeting of expectations. Here, we define information quality as the "ability to satisfy stated and implied needs of the information consumer" [22]. The authors of this definition established a limited set of dimensions to asses information quality (InfoQ) [22], following the statement "the more dimensions are selected for InfoQ, the less comprehensible it is for the users and the more difficult the assessments will become" [18]. Five dimensions (Table 1) have been selected from the original set of InfoQ dimensions. 
Table 1. Information quality dimensions for deviation management, adapted from Gustavsson and Wänström [22]

\begin{tabular}{ll}
\hline $\begin{array}{l}\text { Dimension of } \\
\text { information quality }\end{array}$ & Theoretical definition \\
\hline Completeness & $\begin{array}{l}\text { The extent to which the information is comprehensive for taking action in a } \\
\text { deviation context }\end{array}$ \\
\hline Validity & The extent to which the information measures what it should measure \\
\hline Accessibility & To which extent the information is easy to access when required \\
\hline Relevance & The extent to which the information is appropriate for the tasks and applications \\
\hline Understandability & $\begin{array}{l}\text { The extent to which information is easy to use but also easy to learn and easy to } \\
\text { manipulate, aggregate and combine with other information }\end{array}$ \\
\hline
\end{tabular}

\section{Research method}

\subsection{Research design and empirical setting}

In order to identify different types of deviations occurring in the planning and production processes, the research study employs a qualitative approach using a phenomenological method including interviews, semi-structured questionnaires and on-site observations at five different small and medium sizes Swedish companies. An As-Is analysis of the current existing deviations is made, where root-course analysis is applied to cluster the different types of deviations. Empirical work is set mainly on how the adoption of digital ways of working impact deviation management in the context of SMEs with little to no digitalized data and processes, with a limited budget, limited resources and low technical expertise for developing technical solutions.

Three cluster types of deviations were created based on the source of deviations and including empirical data from the companies, with the unit of analysis being at the factory level. The selection of cluster types is made based on assessing the volume of deviations in terms of appearance at the case companies.

- Deviation A refers to technical disturbances, which comprehends machine breakdown, maintenance, tool change, calibration, fixtures change, change of dies. This category relates directly to machines and production equipment.

- Deviation B refers to resources that comprise personnel, tooling, material (both raw and WIP) missing in the process that causes a stop. Also included in this category is the lack of production plan visibility, change in orders, etc.

- Deviation C refers to quality which comprehends unconformities related to the product that stop the production processes.

The source of data comes from five different manufacturing companies; three being categorized as SMEs and two factories being of SME size $(<250$ employees) while still part of a corporate group. The companies were chosen to provide contrasting cases in order to represent the variety of Swedish SME regarding different types of products, production, and situation. Companies 1 and 2 are contract manufacturers, and all have production of proprietary products except company 2. All companies have flow orientated production, except for company 1 that has functional layout. All have generally high requirements on their product quality. Company 2 having additional 
requirements on documentation and traceability as a subcontractor to aerospace customer. The companies have both machine processing (short and long cycle times) and manual assembly operations. In respect to digitalization to support manufacturing operations, all the companies have only started the transformation, thus representing a vast majority of SME companies. The companies do business in the automotive, maritime, aerospace, and power generation industries. A general description is included in Table 2.

Table 2. Companies description

\begin{tabular}{|c|c|c|c|c|}
\hline $\begin{array}{l}\text { Com- } \\
\text { pany }\end{array}$ & Industry & Interviewees function & $\begin{array}{l}\text { Digital } \\
\text { solutions }\end{array}$ & $\begin{array}{l}\text { Pre-existing } \\
\text { disturbance logs }\end{array}$ \\
\hline 1 & Automotive & $\begin{array}{l}\text { CEO which functions as Quality } \\
\text { responsible and Production } \\
\text { Manager }\end{array}$ & $\begin{array}{l}\text { ERP, In-house } \\
\text { MES } \\
\text { prototype }\end{array}$ & $\begin{array}{l}\text { Technical } \\
\text { disturbances in } \\
\text { paper report }\end{array}$ \\
\hline 2 & $\begin{array}{l}\text { Aerospace \& } \\
\text { power } \\
\text { generation }\end{array}$ & $\begin{array}{l}\text { Operations developer, Quality } \\
\text { coordinator, R\&D manager, } \\
\text { production flow leader, operators }\end{array}$ & ERP, QMS & $\begin{array}{l}\text { About product in } \\
\text { QMS }\end{array}$ \\
\hline 3 & Automotive & $\begin{array}{l}\text { Production supervisor, Plant } \\
\text { manager, Production engineer }\end{array}$ & $\begin{array}{l}\text { ERP, QMS, } \\
\text { MES }\end{array}$ & $\begin{array}{l}\text { Not defined in self- } \\
\text { generated files }\end{array}$ \\
\hline 4 & Maritime & $\begin{array}{l}\text { Production planner, } \\
\text { Supply chain manager }\end{array}$ & $\begin{array}{l}\text { ERP, QMS, } \\
\text { MES }\end{array}$ & $\begin{array}{l}\text { Not defined in self- } \\
\text { generated files, e- } \\
\text { mails }\end{array}$ \\
\hline 5 & Maritime & $\begin{array}{l}\text { Strategic projects manager, } \\
\text { Production planner, Operators, } \\
\text { Team leader }\end{array}$ & ERP, QMS & $\begin{array}{l}\text { About product in } \\
\text { QMS }\end{array}$ \\
\hline
\end{tabular}

Regarding installed digital tools for managing production operations all companies had ERP systems (control level 4 according to the ISA-95 standard [23]) to manage orders, planning, dispatching and managing the material and production flow and transformation stages from raw material to finish products to customers (HybronMPS, Monitor, Jeeves). Also, all companies had digital solutions for the control and automation of equipment and process (ISA-95 level 1 and 2). However, digital tools for level 3 control functions were generally lacking (manufacturing execution systems, MES [24]). Specifically interesting for the present study is that digital solutions for deviation data capturing were lacking in the companies apart from to some extent HybronMPS (company 3) and AXXOS (company 4). All companies employed self-made files to support decision making. The predominant form found was spreadsheets, but they also relied on emails to take information or to track back actions taken in specific cases.

\subsection{Data collection and analysis}

A multidisciplinary team performed semi-structured interviews and fieldwork at each site, along with regular online meetings with all the partners. Data collection consisted of interviews and observations by plant visits. For data analysis, we denote "data" as research notes transcripts, pictures, audio recordings during interviews or meetings, physical documents provided by the company cases, such as charts, organizational diagrams, standardized instructions, company profiles, brochures, visual aids, and whiteboards pictures, etc.

The interviews and data collection were performed with focus on two main areas: first, assessing work procedures and general perceptions on deviations from the personnel, including the report of disturbances, root cause analysis in connection to the deviations and company involvement. The second focus area is on the challenges and capacities i.e. monitoring, control, optimization and autonomy [25] expected to be 
enabled with the implementation of digital tools. The understanding of the capacities implemented is a prerequisite to assess InfoQ regarding the selected dimensions affecting the performance in deviation management (Table 1). The results are discussed in terms of dimensions and the type of digital tools linked to each deviation category and company. The differences and similarities among the deviation categories and companies are revealed to visualize the impact of the implementation.

As a complement to data collection, the research team initiated the empirical work by requesting each company to track all the disturbances taking place at the production floor, for a selected production unit and period of time. No restrictions were given in the form of a logging template, the basic requirement had to do with tracking the time lost due to disturbances and the reason for the stop at all times. These disturbance tracking records/logsheets were aimed at capturing all deviations to get base data to study further. This was initiated since a preliminary study revealed that four of the companies had no technical/digital system in place to record a particular type-set of production deviation, and thus no reliable data. The logsheets also aimed to capture deviations beyond the technical category with the goal to understand the different scenarios, impacts, and types of actions taken on each organization. The logging aimed at making the company both more aware of their disturbances and engaged in an improvement process towards improved disturbances handling.

\section{Results}

\subsection{Disturbance logging}

Four out of five companies performed the manual disturbance logging, as requested by the research team. The company that did not perform the manual logging of the process (company 2) instead decided to prioritize improving their work with disturbances related to the product quality, for which they had information not well utilized.

The logs were performed mostly by the operators working directly at the designated areas. However, in company 3 the logging had to be performed by the production supervisors since operations in the production line did not allow operators to invest time without disturbing the production flow. At company 4, the loggings were made by the production and supply-chain planning responsible. Each company decided data collection approach, following either the products (production order) or focusing on a selected production area/process. Only company 1 adopted the approach to follow a production order due to the nature of their operations. Not many processes were involved in the completion of an order, the production setting is a production job shop type, and the same order could stay more than one day in the same production area or process.

The research team performed the disturbance categorization to ensure correct classification, i.e. the companies recorded all types of disturbances and the researchers categorized the logs.

\subsection{Deviation A on technical disturbances}

The technical deviation type was the starting point of all companies studied, concentrated mostly on deviations and disturbances of machines or production equipment.

In company 3, the ERP system had the functionality to gather stops in the automated equipment (HybronMPS). Only company 4 had a dedicated digital tool for disturbance 
data handling system in place (AXXOS) which allowed them to visualize, track and collect machine and production equipment i.e. downtimes and processing times (manual data input by operators). However, the functions and potential of such a tool were not exploited internally due to not having the technical knowledge or not invested resources. Hence, the personnel was not fully aware of the features and functionalities. Therefore, what kind of data could serve as information for decision making was unknown. The visualizations were employed as informative displaying production processes status (e.g. properly running, under maintenance or breakdown), and alerts emitted were mostly used as an alarm to react and respond to solving those issues. No other case company had such a tool in place. However, it was their desire to have a digital tool of this nature in place with the objective to support decision making, the reason for not having one, fall mostly in the cost-investment for already available solutions. Company 1 relied mostly on the operators as the first option to find solutions when disturbances occurred, if the operators could not find a solution themselves, they submitted a paper-based manual report to the maintenance person responsible, who then took on the responsibility to assess the disturbance and find the solution. Through the project, company 1 developed an in-house MES prototype, which besides allowing them to eliminate paper reports, by design has the potential to visualize and better manage deviations for improved decision-making. The manual logs played a major support role for the assigned students to understand how to develop and program the system.

\subsection{Deviation B on resources}

Category B on resources refers to disturbances where personnel, tooling, material (raw and work in process) are missing in the process, thus causing stops or needs to re-plan production. Also included is the lack of production plan visibility, change in orders, etc.

This category appeared to be the most challenging to capture and connect to the actions taken when a certain disturbance appeared, due to the unawareness of the impact of the deviations. At company 2, this type of deviations was not logged, nor was they very visual to the personnel, apart from daily control and ad-hoc meetings. Worth nothing is that product quality issues (deviation $\mathrm{C}$ ) that forced them to repair products, had a clear effect on the category B-type of disturbances, the availability of production time and personnel resources. Company 3 expressed that a high amount of deviations on daily basis came from missing personnel at the start of the morning shift, and they did not have a way to visualize such gaps. The production supervisor did not have a place where to gather that information, therefore planning and decision making would require some time on daily basis. The logging phase served as a way to acknowledge the issues and see the impact that the lack of information is causing. At company 4, the complexity of production made it difficult for production personnel to see the effects of disturbances, as well as effects of the actions taken to mitigate those disturbances. Missing materials was not a problem, but missing personnel was a major issue that frequently needed to be handled by e.g. re-planning, re-locating personnel, or over-time work. Therefore, at company 4 the logging of these category B-disturbances was prioritized.

At company 5, some disturbances were caused by personnel being lent out occasionally to other workshops since the high volume production was prioritized. Personnel was transferred to the production system studied, having competence for just a few of the tasks in the production system. Also, production operators could be requested, at a short notice, to assist the engineering department (with tests, try-out, preproduction, etc.). Missing components from suppliers was a frequent problem at 
company 5 resulting in re-planning of production schedule and delayed production (delivery). Actions performed in response to a deviation were seldom tracked or recorded.

\subsection{Deviation Con quality}

Category $\mathrm{C}$ on quality refers to disturbances where unconformities related to the product require additional production, repair work, or cause stops the production processes. Four out of the five companies have a digital solution in place to support their QMS, which manages all the disturbances affecting the product, storing deviations' details digitally for access internally and as a requisite from customers. In the five companies, we identified two opposite scenarios for handling this type of disturbances in company 1 and 2 .

Company 1 mostly saved the records related to quality i.e. physical measures to the product, in manual reports as requested by their customer, this was part of their daily operations at each work station. It was their intention to implement a digital system that facilitates the track of records and simplify the work for operators in the long run. There was no digital system in place to record or manage results from such measures neither to say from root cause analysis related to the product quality. Company 2 precisely stated that the only way where there was a track of disturbances and deviations was in their QMS, i.e. all deviations with impact on the quality of the product were reported and tracked in their QMS. For customers requesting it, a root cause analysis was carried out in connection to the disturbances from a quality assurance perspective. Most customers required traceability documentation of all deviations from nominal processes or quality, e.g. repair work of products. At company 3 product quality issues were identified and handled (removed from line) by operators and supervisors in-line. Quality issues were logged manually and classified internally and or externally caused. At company 5 , the products tested half-way in the production flow. The production process were stopped if errors detected, and adjustments were made to avoid disturbance in the future. The most common cause was software errors affecting product design and pre-engineering.

For category $\mathrm{C}$ it was observed that digital tools could support reporting and tracking disturbances, secure standardization, and consistency on the information. The main deficiency relates to the category "understandability" since the information becomes part of quality, it is not easy to use for other purposes, manipulate or combine with other information, also the access may be restricted for certain members in the organization. There is valuable information being gathered for this category that could serve to solve or prevent deviations happening in the other categories at the same company.

\subsection{Methodological limitation in study execution}

A major challenge in the logging process of the case companies had to do with tracking the mitigating actions of disturbances. In most companies, such actions were not logged, which means there was no historical record about what happened after the appearance, how it was solved, lessons learned and root causes. The commonly observed form of tracking disturbances were whiteboards. After a disturbance had been solved it was immediately erased from the board, and actions and responsibility disappeared, i.e. if a disturbance re-appeared the organizations would need to rely on workers know-how.

Another challenge in the manual logs had to do with the accuracy of the reports, due to the fact that production times did not necessarily match the manual logs and the ERP systems of the companies. All five companies used an ERP system mostly employed for production planning activities and not connected directly to reflect the disturbances and 
impact in production planning and other areas once a disturbance occurred. Self-made documents such as spreadsheets were employed as a way to keep track of changes, for example in company 5 , where if missing parts affected the production plan, the change in the priority of the order was reflected in an Excel spreadsheet that comprised the daily production plan. This document was managed by the production planner and available to production personnel in a shared document on the production shop floor.

\section{Discussion}

The empirical findings indicate the need for the companies to perform more careful requirement analyses to assess their current state in terms of data and information before implementing digital systems or digital tools. Actual inputs and requirements may differ from the current discourse about SMEs needing to engage in a "Digital agenda" and rush to address the urgency of the "Digital transformation" [14].

Findings also indicate that a general conceptual solution can not be applicable for implementing digital solutions in specific companies. There is no 'one-size-fits-all' approach to the adoption and use of IT that takes into account specific needs and expectations of SMEs, as well as their specific characteristics and contingencies from the environment [14]. An individual transformation process and approach is required in order to identify, evaluate and exploit the specific industrial potentials [11], [12].

Based on the analysis of how data collection of deviations was carried out at the five case companies as well as analyzed and used, the preliminary contribution to guidelines on technology implementation towards DT could be summarized:

1. Understanding the company requirements for visualization of information that is crucially needed is essential as the starting point. What is needed from different functions in order to achieve added value?

2. Assessment of existing data and information inventory is a mandatory step before any acquisition, including dimensions of information quality.

3. Analyzing the integration of digital elements in existing solutions should be made, i.e. is it possible to upgrade or implement elements in current systems that give the same/similar outcome? In addition, is knowledge lacking of how to utilize functionalities in current digital solutions?

4. Stepwise implementation is recommended, i.e. of digital technologies that fit the information need and allow SMEs to cope with the required technical development and investment.

In the research study, it was encountered that the companies with more digital elements already incorporated in their production systems did not necessarily have better deviation management than those lacking such digitalization support. On the contrary, the presence of more digital systems and tools could result in more information silos that were not necessarily connected or exchanged. Assessing the five dimensions from the information quality perspective gives an understanding of whether or not a certain applied digital tool was fulfilling the need it was initially intended for. It also highlights the impact (whether it was positive or negative) such technology had on deviation management. 
The research demonstrates that digital tools could support data gathering and facilitate the logging process in the long term, in comparison with manual logs (as done in these cases) which requires valuable time to be spent on logging during running production. Digital data can thus be more reliable and trustworthy.

The data quality and quantity are two aspects that challenge the utilization of digitalization. Meaningful information can only be inferred from the data if both quantity and quality are sufficient, quality referring to both correctness and how well it meets the needs. Both aspects are highlighted as potential drawbacks for DT by different publications [1], [26], [27]. In many cases where the information is analog, or when there is no procedure in place to collect any disturbance information, neither to say assess the quality of the information, the introduction of digital tools could improve information quality and quantity. This would directly impact the performance of deviation management as the decision making then can be based on verifiable data rather than blindly or by own biased knowledge. However, the information quality could certainly be an issue also when digital disturbance logging is used, since many times identification and classification of disturbances are not automatic but done by the operators.

With the utilization of MES, the companies expect to have more control on their processes in relation to deviations type A. However, it was observed that those companies that already had a MES or digital tool in place tracking production machines and equipment were not necessarily better at handling related deviations. It is observed that the companies perceive it as a natural and easier point to start implementing digital tools for handling deviations of type A. However, it was also observed that type A deviations could be caused by deviation type B. This was observed in company 3 , were category A was not a concern, they could visualize and track stops digitally but still presented high occurrence on resource disturbances.

Deviations on category B are the least tracked and controlled by the companies, there is a lack of visibility which relates to unawareness of the impact, which translates to low efforts to manage the deviations. Therefore, the use of digital tools to enable visualization of these sources of deviations (to start with) is a promising area to explore for companies.

Product quality deviations $\mathrm{C}$ were documented and handled by all companies, although in company 1 manually without digital QMS. Interesting for this type of deviation is that the impact that these have (because of re-work/repair) on production plans, additional use of the resource (operators, machines, time) are not apparent or visual to production, and not optimally handled.

Table 3 contains a summary of the evaluation of the information quality dimensions, for information of the three types of deviations, the mark indicates the dimensions that present deficiencies and that could be enhanced. We can notice that deficiencies are still present even in the situations where the digital tools are in place, the main scarcities relate to the ability to manipulate the information, also that information must be "easy to use" and "easy to learn" from.

Table 3. Information quality dimensions by study case ( $\otimes$ indicate deficiencies in the information)

\begin{tabular}{lccccc}
\hline Deviation & Completeness & Validity & Accessibility & Relevance & Understandability \\
\hline Deviation A & $\otimes$ & $\otimes$ & $\otimes$ & $\otimes$ & $\otimes$ \\
\hline Deviation B & $\otimes$ & & $\otimes$ & $\otimes$ & $\otimes$ \\
\hline Deviation C & & & $\otimes$ & & $\otimes$ \\
\hline
\end{tabular}




\section{Conclusions, limitations and future work}

The research demonstrates the value for SMEs to understand their information needs, in order to define what data is needed to achieve the required information. The digital systems can with high certainty aid to provide the information essential to accomplish precise disturbance handling; which means with the right priority, at the right time and in compliance with the organizational KPIs. In this regard, all areas involved should be able to "sense" disturbances directly when they occur, provide feedback information right away, and communicating this to relevant functions at the factory level. The initial impact on the utilization of digital tools for deviation management in SMEs relates to the trustworthiness of the data since the digital tools enable companies to convert the required data into information they can trust for optimal decision-making. However, the next challenge for SMEs translates to needs' analysis and understanding the differences between what information is needed vs wanted.

The limitations of the empirical studies fall on the generalization aspect, due to the companies being from different industries and having different objectives for the adoption of digital tools. However, this was used as a positive setting to observe diverse possible outcomes from the application stages of digitals tools at each environment that the companies in the study represent. Companies being more advanced in the transition can serve for providing lessons learned to the others at earlier stages, an example of this benefit, is the feedback the project was able to provide to company 1 during development of their in-house MES tool. Advanced companies can utilize the other to widen their perspective on their current use of digital tools, and increase utilization.

Advanced stages of the project will opt for a proactive response instead of the observed reactive actions. In the ideal state, once a deviation has occurred, the disturbances management process should determine quickly and efficiently how the deviation is best managed and at what cost, that allows for accurate and objective decision-making. This would then lead to a high robustness of production and logistics as envisioned. The research aims to give SMEs an understanding on the utilization of digital tools for supporting disturbance handling and support decisions on automation and digitalization investments on the production shop floor. Further research should be devoted to a real case business model for DT in the SME context.

\section{Acknowledgment}

This work has been carried out within the project ASPIRE "Automation solutions for production deviation management", funded by Sweden's Government Agency for Innovation VINNOVA (Programme Produktion2030). We gratefully acknowledge the funding, as well as good collaboration and support from the participating companies.

\section{References}

[1] J. Lee, B. Bagheri, and H. A. Kao, "A Cyber-Physical Systems architecture for Industry 4.0-based manufacturing systems," Manuf. Lett., vol. 3, pp. 18-23, 2015.

[2] M. Wieland et al., "Towards a Rule-based Manufacturing Integration Assistant," Procedia CIRP, vol. 57, pp. 213-218, 2016.

[3] R. L. Gomes, M. Rigley, D. Bacon, N. Watson, L. Porcu, and O. Fisher, "Cloud manufacturing as a sustainable process manufacturing route,” J. Manuf. Syst., vol. 47, pp. 53-68, 2018. 
[4] M. Brettel, N. Friederichsen, M. Keller, and M. Rosenberg, "How virtualization, decentralization and Network Building Change the Manufacturing Landscape: An Industry 4.0 Perspective,” vol. 8, no. 1, pp. 37-44, 2014.

[5] P. Dallasega, R. A. Rojas, E. Rauch, and D. T. Matt, "Simulation Based Validation of Supply Chain Effects through ICT enabled Real-time-capability in ETO Production Planning," Procedia Manuf., vol. 11, no. June, pp. 846-853, 2017.

[6] T. Ylipää, A. Skoogh, J. Bokrantz, and M. Gopalakrishnan, "Identification of maintenance improvement potential using OEE assessment," Int. J. Product. Perform. Manag., vol. 66, no. 1, pp. 126-143, 2017.

[7] J. M. Müller, O. Buliga, and K. I. Voigt, "Fortune favors the prepared: How SMEs approach business model innovations in Industry 4.0," Technol. Forecast. Soc. Change, vol. 132, no. December 2017, pp. 2-17, 2018.

[8] J. M. Müller, D. Kiel, and K. I. Voigt, "What drives the implementation of Industry 4.0? The role of opportunities and challenges in the context of sustainability," Sustain., vol. 10, no. 1, 2018.

[9] K. Vogelsang, K. Liere-Netheler, S. Packmohr, and U. Hoppe, "Success factors for fostering a digital transformation in manufacturing companies," J. Enterp. Transform., vol. 0, no. 0, pp. 1-22, 2019.

[10] A. Mukhopadhyay, L. R. D. Murthy, M. Arora, A. Chakrabarti, I. Mukherjee, and P. Biswas, "PCB inspection in the context of smart manufacturing," vol. 135, Singapure: Springer Singapore, 2019, pp. 781-791.

[11] B. M. Ernst Pessl, Sabrina Romina Sorko, "Roadmap Industry 4.0 - Implementation Guideline for Enterprises,” Int. J. Sci. Technol. Soc., vol. 5, no. 6, pp. 193-202, 2017.

[12] V. G. engineering Federation, "Guideline Industrie 4.0: Guiding principles for the implementation of Industrie 4.0 in small and medium sized companies," 2016.

[13] N. Ganzarain, Jaione; Errasti, “Three stage maturity model in SME's toward industry 4.0," J. Ind. Eng. Manag., vol. 9, pp. 1119-1128, 2016.

[14] J. Reis et al., "Digital Transformation: A Literature Review and Guidelines for Future Digital Transformation : A Literature Review and Guidelines for Future Research," J. Small Bus. Enterp. Dev., vol. 26, no. 6-7, pp. 855-876, 2019.

[15] A. Ustundag and E. Cevikcan, Industry 4.0: Managing The Digital Transformation. 2018.

[16] Z. Bi et al., "Real-time force monitoring of smart grippers for Internet of Things (IoT) applications," $J$. Ind. Inf. Integr., vol. 11, no. February, pp. 19-28, 2018.

[17] M. S. Boorla, T. Eifler, C. McMahon, and T. J. Howard, "Product robustness philosophy - A strategy towards zero variation manufacturing (ZVM)," Manag. Prod. Eng. Rev., vol. 9, no. 2, pp. 3-12, 2018.

[18] F. Naumann, "Quality-driven query answering for integrated information systems," Humbolt Universität zu Berlin, 2002.

[19] C. Martínez-Olvera and J. Mora-Vargas, "A Max-Plus Algebra Approach to Study Time Disturbance Propagation within a Robustness Improvement Context," Math. Probl. Eng., pp. 1-18, 2018.

[20] M. Morisse and C. Prigge, "Design of a Business Resilience Model for Industry 4.0 manufacturers," in Twenty-third Americas Conference on Information Systems, Boston, 2017, 2017, pp. 1-10.

[21] J. G. Timmerman, J. Boer, M. Hisschemöller, and W. Mulder, "Specifying information needs: improving the working methodology," Reg. Environ. Chang., vol. 2, no. 2, pp. 77-84, 2001.

[22] M. Gustavsson and C. Wänström, "Assessing information quality in manufacturing planning and control processes," vol. 26, no. 4, pp. 325-340, 2009.

[23] IEC, “ANSI/ISA-95.00.01-2010 (IEC 62264-1 Mod) Enterprise-Control System Integration - Part 1: Models and Terminology," IEC 62264-1 standard, 2013. [Online]. Available: https://www.isa.org/.

[24] B. K. Choi and B. H. Kim, "MES (manufacturing execution system) architecture for FMS compatible to ERP (enterprise planning system)," Int. J. Comput. Integr. Manuf., vol. 15, no. 3, pp. 274-284, 2002.

[25] A. Moeuf, R. Pellerin, S. Lamouri, S. Tamayo-Giraldo, and R. Barbaray, "The industrial management of SMEs in the era of Industry 4.0," Int. J. Prod. Res., vol. 56, no. 3, pp. 1118-1136, 2018.

[26] R. Dubey, A. Gunasekaran, S. J. Childe, S. Fosso Wamba, D. Roubaud, and C. Foropon, "Empirical investigation of data analytics capability and organizational flexibility as complements to supply chain resilience," Int. J. Prod. Res., vol. 0, no. 0, pp. 1-19, 2019.

[27] J. Lee, B. Bagheri, and C. Jin, "Introduction to cyber manufacturing," Manuf. Lett., vol. 8, pp. 11-15, 2016. 